\title{
Using a Cooperative Educational Game to Promote Pro-Environmental Engagement in Future Teachers
}

\author{
Mercedes Vázquez-Vílchez *, Dalia Garrido-Rosales, Beatriz Pérez-Fernández and Alicia Fernández-Oliveras \\ Departamento de Didáctica de las Ciencias Experimentales, Universidad de Granada, 18071 Granada, Spain; \\ daliagarrido@correo.ugr.es (D.G.-R.); beatrix22@correo.ugr.es (B.P.-F.); alilia@ugr.es (A.F.-O.) \\ * Correspondence: mmvazquez@ugr.es
}

check for updates

Citation: Vázquez-Vílchez, M.; Garrido-Rosales, D.; Pérez-Fernández, B.; Fernández-Oliveras, A. Using a Cooperative Educational Game to Promote Pro-Environmental Engagement in Future Teachers. Educ. Sci. 2021, 11, 691. https://doi.org/ 10.3390/educsci11110691

Academic Editors: José Carlos Piñero Charlo, María Teresa

Costado Dios, Enrique

Carmona Medeiro and

Fernando Lloret

Received: 23 August 2021

Accepted: 24 October 2021

Published: 29 October 2021

Publisher's Note: MDPI stays neutral with regard to jurisdictional claims in published maps and institutional affiliations.

Copyright: (c) 2021 by the authors. Licensee MDPI, Basel, Switzerland. This article is an open access article distributed under the terms and conditions of the Creative Commons Attribution (CC BY) license (https:/ / creativecommons.org/licenses/by/ $4.0 /)$.

\begin{abstract}
This paper explores the value of cooperative games in enhancing knowledge and generating pro-environmental engagement in students. For this, an educational board game related to global change was developed, validated, and subsequently evaluated using future primary school teachers. The board game was validated and evaluated in two phases. Phase I (validation phase): students pursuing a Master's Degree in Secondary Education evaluated different aspects of the game, providing feedback that improved the game design and playing rules. Phase II (implementation-evaluation phase): the game was implemented using students of the Primary Education Degree, whose learning performance and engagement was assessed through a qualitative survey. These participants were considered potential users of the board game. The users' experience was explored using a theoretical framework for pro-environmental engagement through playing the game. The findings demonstrate that the cooperative game proposed fomented a feeling of personal responsibility for the environment in the users. It also fostered cognitive, emotional, and behavioural engagement in the players. The results agree with the attributes present in the framework of engagement with respect to climate-change-related issues using gaming. Game-based learning can be used as a tool for enhancing global change knowledge and promoting pro-environmental engagement while bolstering Education for Sustainability (EfS) capacity in future primary-school teachers.
\end{abstract}

Keywords: game-based learning; board games; global change; environmental engagement; teacher training; higher education; Education for sustainabieducation for sustainabilitylity

\section{Introduction}

Programmes such as the United Nations Decade of Education for Sustainable Development have made global calls to teach about the global environmental crisis, in order to encourage changes in knowledge, values, and attitudes with the vision of building a more sustainable and fairer society for all. These calls, increasingly reflected in formal and non-formal education settings, are expressed in international assessments of science education [1]. However, although the public has been progressively becoming aware of environmental issues, a discrepancy persists between the convictions expressed and the behaviour of large segments of society [2]. Thus, an awareness of an environmental problem is needed to motivate pro-environmental action, which may be strengthened by understanding the link between an individual's actions and subsequent environmental decline [3]. According to Bamberg [4] an important precursor of pro-environmental action is a feeling of personal responsibility for the environment-which also involves being aware of how one's actions negatively impact nature. Such personal environmental norms have been shown to predict pro-environmental behavior, such as choosing sustainable modes of travel [5] and preserving marine environments [6]. In this sense, Education for Sustainability (EfS) should encourage the feeling of personal responsibility to initiate pro-environmental behaviour. Therefore, EfS needs to be established as a key purpose of scholarly education but ensuring good teacher training in EfS is a major challenge [7-9]. 
This paper explores the role of game-based learning in expanding knowledge and fostering pro-environmental engagement. To this end, an educational board game based on global change (GC) was developed and validated. GC is a complex term still widely confused with climate change. GC refers to the ensemble of environmental changes provoked by human activities, especially changes in the functioning of the Earth's systems. GC includes at least five components: atmospheric composition, soil use, climate, biochemical cycles, and biodiversity. These components are interconnected in such a way that, if one of them is altered, the characteristics of the others will also change [10]. Our study is in line with other authors who propose educational games and gamification for climate-change engagement [11], but no study available has treated climate change as a part of GC, which is key in EfS, since climate-change is only one factor to take into account in order to promote pro-environmental engagement. We implemented the game using students of the Primary Education Degree, while learning performance and engagement were evaluated through a qualitative survey. This paper provides an evidence-based case study that offers insight into the learning and experiences of students after playing an environmental game, which demonstrably enhanced engagement in the future primary teachers. This approach may be of use to others in the sustainability community considering cooperative game-based learning and teaching opportunities.

\section{Game-Based Learning and Engagement}

\subsection{Game-Based Learning Approach}

The game-based learning approach has been largely recognized as one of the best active educational approaches [12,13]. It is a type of gameplay with learning outcomes, making it distinct from entertainment-oriented formulas. Game-based learning is designed and developed for the primary purpose of educating or training students [14,15].

Extensive research involving game-based learning provides the empirical evidence that supports diverse cognitive benefits [16-18] accompanied by affective and motivational changes $[19,20]$; however, some studies qualify this view and suggest that while games have value within teaching and learning, their effectiveness in improving student performance is influenced by the design of the game and the specific instructional purpose [21]. Wouters et al. [22] acknowledged that game-based learning interventions are often short, consisting of only one session and thus limiting their possible learning impact.

Although more research is required to establish the long-term outcomes of games on student achievement and deeper learning [23], there is evidence to suggest that playing games can improve student learning and engagement [24]. Core traits within games offer opportunities to change behaviours and develop learning [25]. These include uncertainty, i.e., the inability to fully predict or control processes related to outcomes, and non-linearity, i.e., the interaction among a game's elements that can generate different outcomes. Games could provide opportunities to change behaviours, develop ideas, and encourage collaboration within the safe environment of a game $[24,26]$, thus, the game can enhance students experiences and engagement through peer-to-peer learning, collaboration, negotiation, and problem solving [27]. Moreover, game-based learning is a didactic strategy that facilitates experiential learning, given that the users attempt to reproduce a context as close to reality as possible [24]. Experiential learning seeks to engage students through education and entertainment, where students develop critical thinking skills and generate an emotional response. Some authors have highlighted the capability of game-based learning to engage and motivate students who no longer find traditional learning and teaching styles appealing [24-26]. Cooper et al. [28] suggests this is due to games' ability to harness collaborative problem-solving skills. Therefore, student engagement and motivation, so closely related in the learning process, are crucial advantages of game-based learning over traditional instruction, thus, it is only natural that researchers frequently focus on these aspects as a key aspect of instructional games $[25,26]$. 


\subsection{Engagement and Motivation}

The concept of engagement has many connotations. One such example of this is player engagement, which is related to the experience of playing games and linked to a multitude of other concepts such as flow [29], immersion [30] and motivation [31]. On the other hand, the student engagement concept has a multifaceted nature and is defined in three subdomains (behavioral, emotional and cognitive engagement). Behavioral engagement encompasses student participation; it includes involvement in activities and is significant in the achievement of learning outcomes [32,33]. Emotional engagement covers both positive and negative reactions to instructors, classmates, and schools, and it is thought to build connections with others and reflect the willingness of students to complete tasks [31,34]. Finally, cognitive engagement incorporates student investment, and it influences the thoughtful efforts of students to understand complex knowledge and master difficult skills $[35,36]$. For this study, we have considered the concept of engagement as used in climate change research, specifically that proposed by Lorenzoni et al. [37], who defines engagement with climate change as the individual evaluation of and response to climate change which comprises cognitive, emotional and behavioural components. We have chosen this approach because it comes closest to the aim of our study, as it provides a framework for categorising those responses of our students that show a personal connection not only to climate change, but to other environmental issues included in GC.

Lorenzoni et al. [37] suggests that it is not enough for people to know about climate change, but that "they must also care about it, be motivated and able to act" to engage with climate change. Hence, the definition of engagement includes all three dimensions: cognitive, emotional and behavioural. Thus, in order to become more engaged with climatechange-related issues, in our case GC, players will: (a) think more about and possibly learn more about it (b) feel more personally involved, i.e., give more importance to the issue; and (c) make behavioural changes to express their concern.

The motivation to play is strongly related to motivation grounded in activity specific incentives [38]. In this way, the activities proposed in game-based learning can motivate students, increasing their learning outcomes and problem-solving skills [39]. Game-based learning can also develop both extrinsic and intrinsic motivation in students [40]. Intrinsic motivation is defined as the doing of an activity for its inherent satisfaction rather than for some separable consequence, while extrinsic motivation is incentivized with the acquisition of reinforcers [41]. Game-based learning can increase the student's intrinsic motivation, for example, when they feel recognition from, and sense of belonging to, a group [42]. Games can also use different mechanics and dynamics, highlighting, for example, the points-badges-leaderboards triad [43] and enhancing extrinsic motivation, which in excess could have a negative impact on the intrinsic motivation of students [41]. In this sense, to keep users engaged is especially important to foment intrinsic motivations [44,45].

\subsection{Game-Based Learning for Sustainability}

The literature offers many examples of specific game-based learning studies on EfS [11,46-48]. These games address a wide range of learning goals, from increased knowledge to enhanced pro-environmental engagement [49,50], and involve the use of different formats (i.e., digital, board game, and hybrid).

Board games appear to be an excellent learning tool to use for EfS, usually being designed as social activities [11]. According to social constructivist theories, ideas are built through social interaction [51], which is an effective strategy in terms of EfS [52]. Moreover, the board game platform creates a small virtual society in which students can learn by trial and error and accumulate experiences in a virtual world. Based on the scenario around which the theme of a board game is designed, different events can be simulated. Moreover, board games are highly interactive. In these games, students can take the initiative to explore and exchange information with their peers, thus promoting student-centred learning. With board games, participants play face to face, engaging in human-to-human interactions (interactions among players) and human-to-board game 
interactions (feedback provided to players by board game mechanisms). Students explore the world of the board game and its mechanisms as beginners and, through feedback and player interaction, gradually become familiar with the rules and value systems of the game $[48,53,54]$.

In fact, there are numerous examples of board games that present several opportunities to explore multiple facets of sustainability. For instance, the Keep Cool game covers and integrates central biophysical, economic, and political aspects of climate change [52]. Water Ark, enhances participants' knowledge about water resources [53]. The theme of the Crazy Water board game simulates the water use habits of residents in their daily lives [54]. The Enviropoly game works with daily life behaviours, which have negative or positive effects on the environment, promoting environmental literacy [55]. The Forage Rummy game can be used to educate farmers in climate change [56]. The Let's Save Energy! game is focused on international and environmental cooperation against climate change [57] and, finally, in Be Blessed in Taiwan [46,47], sustainable development concepts are introduced into the play process. This board game addresses four related aspects: social development, economic growth, environmental protection, and animal survival. In this paper, we offer a new game based on GC, where its five components are equally addressed, presenting students with a global view of environmental issues, unlike the many climate change games we have identified in the literature [11].

Although sustainability games have begun to be implemented in educational settings, academia knows little about how gaming works with environmental topics, what its characteristics and actual performance are, or how much potential it has to foment awareness, engagement and behavioural change $[11,58]$. In this way, there are few theoretical frameworks that provide a comprehensive vision of which factors should be considered in games to promote pro-environmental behaviours.

Recently, Ouariachi et al. [59] provided a theoretical framework which indicates those game attributes that should be considered in order to motivate people into action. These attributes are the following: (1) achievable; (2) challenging; (3) concrete; (4) credible; (5) efficacy enhancing; (6) experiential; (7) feedback oriented; (8) fun; (9) identity-driven; (10) levelling-up; (11) meaningful; (12) narrative-driven; (13) reward-driven; (14) simulating and (15) social. This framework identifies which of these attributes prompt deep engagement, representing those that simultaneously produce cognitive, emotional and behavioural engagement [37]. According to these authors, pro-environmental engagement through games is achieved by experiential learning and with powerful narratives. The information should be concrete and credible to connect with people's experience and values. An engaging experience should also be fun with challenges that include achievable goals. When these factors are associated with social interactions and peer pressure, there is more chance that behavioural change will occur.

\section{The Board Game: A Planet Near the Abyss}

As a proposal devoted to EfS, we designed and manufactured a board game intended to enhance undergraduate students' knowledge and understanding of GC and encourage pro-environmental student engagement [60]. In order to motivate people into action, the attributes proposed by Ouariachi et al. [59] were considered in the game design.

A cooperative board game design was used because we intended to enhance social interaction, because social elements in games constitute a major category for fostering affective and behavioural engagement [11]. Such collaborative mechanics should enable the occurrence of changes in attitude towards sustainability or the environment [61]. In addition, some studies have indicated that multiplayer role-plays seem to enable empowerment regarding environmental issues [62] and increase awareness of collaboration [63].

Many works propose experiential learning as a good model for EfS $[59,64]$, therefore, experiential learning was pursued in the game design by affording hands-on experiences in a simulated context, providing different levels of abstraction and focusing on the features 
of GC, along with including moments for individual or group reflection. It goes without saying that we also sought to offer students an interesting and enjoyable experience.

The game proposed for GC education is called A Planet Near the Abyss, which was inspired by a commercial cooperative board game called Forbidden Island created by Matt Leacock and distributed by Devir Iberia and Gamewright ${ }^{\circledR}$. Like Forbidden Island, our educational board game is designed for two to six players. Since it is a cooperative game, all the players comprise a team and if a member of the team loses, all the other members also lose and the game is over.

The narrative-driven approach is inspired by the Forbidden Island game, which may promote a deep student immersion in the game environment and thus increase their motivation [65]. The game involves 23 different ecosystems (Figure 1), some natural and others anthropic, each represented by a different tile. One side of the tile displays an image of the ecosystem, and the other side has an image of the same ecosystem that is affected by GC. The tiles that reflect the ecosystems affected by GC show shocking images for provoking meaningful, emotions, which could influence player motivation, attitudes and values $[66,67]$. The ecosystems were chosen for being currently affected by GC or for their vulnerability to be affected in the near future. Some examples of the natural ecosystems include coral reefs, mangrove forests, and Mediterranean forests. Additionally, we added anthropogenic ecosystems, such as London, Polynesia, and Norilsk. In these cases, both sides of the tiles are the same, because GC has already affected these ecosystems, and so it is not a prediction, as in the rest of the board tiles [68]. Players take turns moving their pieces around the board and movements on the board must be crosswise, never diagonal. A spaceship appears on the board and this is because the goal of the game is to rescue the four endangered animal species (African elephant, caribou, orangutan and Iberian lynx) within their corresponding ecosystems (savanna, tundra, jungle and Mediterranean forest), to travel to the space station on a rocket in order to safeguard these species, and to continue research on how to save the planet. In this way, the students would become the heroes that save the planet, with meaningful feelings such as efficacy-enhancement or confidence for an increasing sense of empowerment to act [11,59]. The purpose of our game is to create inspiring characters as a powerful strategy to achieve an emotional connection, since such characters can reflect the human aspects of GC. Therefore, the aim is to create identity-driven qualities that emerge when connections are made between the game and the personal experiences of the players.

The game has two packs of cards, one for conservation and one for impact. Each impact card explains how GC affects a given ecosystem and implies that the ecosystem tile has to be turned around towards the side affected by the GC. The conservation cards consist of seven Species cards, four Habitat Protection cards, three Escaping by Spaceship cards, and five Ecologist cards (Figure 2). The Species cards allow players to save endangered species. The Habitat Protection cards allow ecosystem tiles to be restored by turning them to the side unaffected by GC. The Space Escape cards allow players to escape the planet once they have saved the four endangered animal species. The cards for the ecologists ask questions or pose challenges regarding the GC that the students must resolve by working together. The questions or challenges set out on these cards require reflective work from the students while enhancing their GC knowledge. In addition, there needs to be agreement on which player rescues which endangered species, depending on their position on the board. We have included 10 Ecologist cards: two cards for each component of GC. The Ecologist cards aim to improve understanding of environmental issues. These cards address issues such as the effect of anthropogenic factors on biodiversity conservation, biochemical cycles and their relation to ecological successions, air pollution, human-induced climate change, and overpopulation and its consequences (deforestation, fires and overexploitation). Concrete and credible information is integrated into the game mechanics through impact cards, avoiding extensive and complex analyses. It has been our objective to offer challenges with achievable goals, as proposed by Waddington and Fennewald [69]. These authors demonstrated that affective issues, including induced fatalism, can be provoked through 
making challenges in games extremely difficult, which reduces student motivation and engagement. Challenges are designed for the consequences of decisions, and the actions taken in the game represent the feedback players receive and replicate in real life, so this feedback should be positive and encouraging [59]. Thus, the challenges in our game would be considered feedback oriented.

Over the course of the game, cards are drawn in each turn: two from the conservation pack and either three or one from the impact pack (if the players' answer to the Ecologists' card is correct). When the same impact card comes up twice during the game, the ecosystem tile is removed from the board and players lose mobility. If this happens on the ecosystem tiles where endangered species live, or on the spaceship tile, then the players lose the game. An endangered species can be saved if a player obtains four cards for that species and locates those cards in the ecosystem where the species lives or in adjacent tiles. The game has a risk marker, which shows the degree of harm caused by GC. The risk increases whenever a player receives a card for an ecologist. If the players reach the top of the risk marker and they have been unable to save all endangered species, they lose.

The game, A Planet Near the Abyss, has three levels: beginner, medium, and advanced. The different levels provide suitable changes to connect to the prior knowledge of young people and, hence, the game is challenging with different tasks that require effort to perform. Therefore, the students can become aware of the consequences that their actions have for our planet, and this can induce them to reflect on how our lifestyles can affect the environment. In addition, players would be able to replay the levels to practice their skills before moving on to the more difficult levels [70]. Levelling is also important for motivating behavioural change because people can feel safer and closer to their goal than they might have expected [71].

To facilitate the explanation of the instructions, we developed a video tutorial that places students in the game context and indicates the goal to achieve in order to win the game, as well as the steps required to be undertaken (https: / youtu.be/Q6jnZXIEYTw, accessed on 26 October 2021).

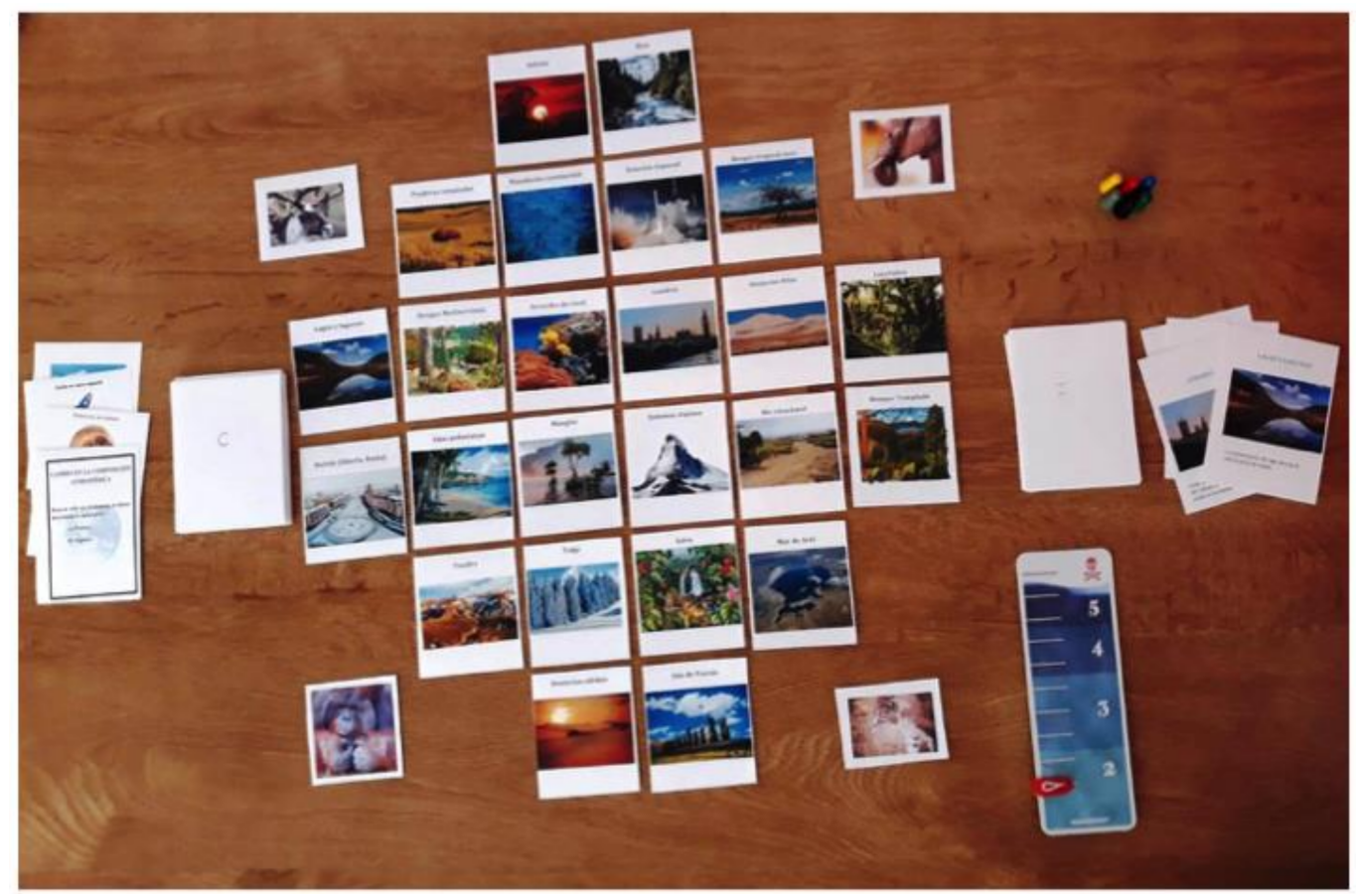

Figure 1. A Planet Near the Abyss board game. The board, representing the planet Earth, is composed of 23 ecosystems affected by global change, each represented by a different tile. 


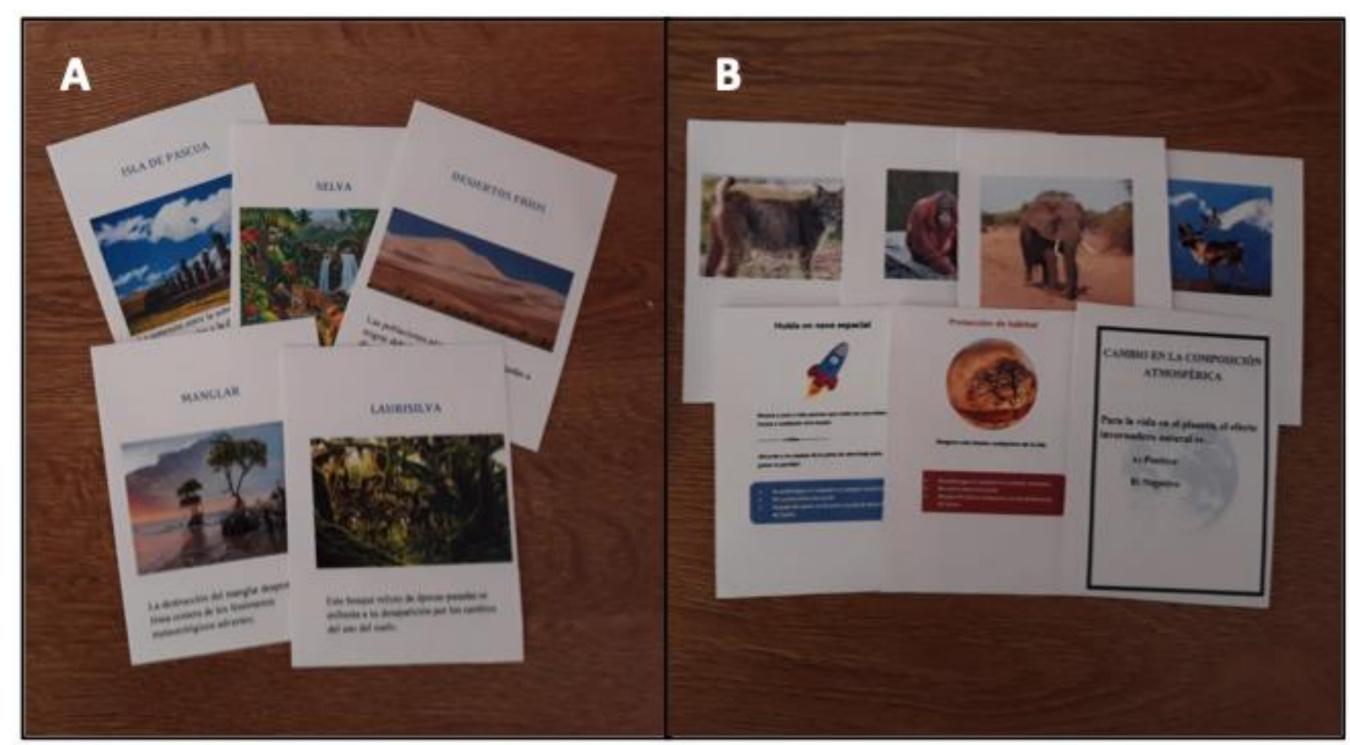

Figure 2. Packs of cards of the game, A Planet Near the Abyss. (A) Impact cards explain how global change affects a given ecosystem; (B) Conservation cards: 7 Species cards, 4 Habitat Protection cards, 3 Escaping by Spaceship cards, and 5 Ecologist cards.

\section{Materials and Methods}

\subsection{Study Participants and Procedure}

The board game, A Planet Near the Abyss, previously designed by the Authors [60], was validated, implemented, and evaluated in two phases:

- $\quad$ Phase I (validation phase), in which different aspects of the game were evaluated by 6 volunteers ( 4 women and 2 men between the ages of 26 and 28), who were students of the Master's Degree in Secondary Education (K-12) (Biology-Geology specialty), a demanding programme requiring high grades for admittance. These participants were considered experts and qualified evaluators of the educational game, since they were science graduates who, as future secondary teachers, had shown high performance and strong motivation in EfS. In addition, their ages and the cultural context in which they had been educated were closer to those of the potential users of the game. This could be relevant to a proper appraisal of the playability of the game by the current students. The feedback generated during this phase improved the game design and playing rules.

- Phase II (implementation-evaluation phase), in which the game was implemented with 128 students of the Bachelor's Degree in Primary Education (K-6) (90 women and 38 men between the ages of 20 and 25). This study formed part of the Science Education subject of the third course in the degree. The students were split into four groups of approximately thirty-two each. Four tutors were present in the classroom and they acted as guides during the game. After the students played the educational board game for $2 \mathrm{~h}$ in a classroom, the learning performance, dimensions of engagement [37], and engagement regarding climate-change-related issues through serious gameplay [59] were evaluated. These participants were considered potential users of the board game, being future primary school teachers interested in broadening their knowledge concerning environmental issues.

\subsection{Analysis of the Validation Phase}

After playing the educational game, the Master's students filled out a questionnaire that evaluated the usability of the game and analysed its communicative and educational elements through items with multiple answers and open questions.

The items for the evaluation of usability were chosen based on the questionnaire, "System Usability Scale" (SUS) [72], to evaluate usability and functionality. This question- 
naire was made up of 4 -scale Likert items valued from 1 to $4(1=$ "strongly disagree", $2=$ "disagree", $3=$ "agree" and $4=$ "strongly agree"), and two open questions to gather opinions on how to improve the usability and strengths of the game. An even number of scales in the Likert questionnaire was chosen in order to avoid unnecessary neutral responses [73,74].

As a means of evaluating the communicative and educational aspects of the game, the dimension proposed by [75] was adapted, selecting the criteria that fit our game. Three dimensions were evaluated: 6 items were prepared to evaluate the Gameplay dimension (number of players, type of game, duration, dynamic, objective and entertaining); 3 items concerned the Contents dimension (relevant, story and terminology); and 2 other items served to assess the Educational dimension (competence development and skills). The items were valued according to the Likert scale (from 1 "strongly disagree" to 4 "strongly agree") and at the end of each aspect an open question was asked to gather proposals for improvement. A general rating scale from 1-10 was used for a question to determine the overall assessment of the game. Another question asked whether the participants would use the game as teaching material in their classes, with a possible answer between three options, "Yes", "No", and "Maybe", and there was a final open question to establish their general opinion of the game.

\subsection{Analysis of the Implementation-Evaluation Phase}

The authors used a short qualitative survey to explore the learning performance and student engagement from students of the Bachelor's Degree in Primary Education after playing a GC game. Thematic analysis $[76,77]$ was used on data collected through open questions. Examples of students' answers were translated from Spanish to English. These answers, containing information vital to this research project, are compiled in the Results section. Reliability of the data analysis was assessed twice according to procedure, i.e., following the pilot and the main phase of the analysis [77]. For the main phase, the intra-dimension reliability was $80 \%$, where the students' answers were coded at two points in time.

The learning performance about GC was evaluated through two pre-test and post-test open questions:

Q1. "What is GC and what consequences does it have?"

Q2. "Do you think that something you do affects GC? If so, indicate what."

The data compiled in the first question were structured into main categories or dimensions, most of which were based on preconceived subjects related to existing knowledge concerning GC. In this sense, we categorized the students' answers according to the definition of GC, as a "set of environmental changes affected by human activity, with particular reference to changes in the processes that determine the functioning of the Earth system " [10] (p.23), and we also used their five components as categories. Therefore, the students' ideas were categorized and quantified in relation to GC: (1) environmental changes; (2) human activity; (3) Earth system disturbance; (4) changes in atmospheric composition; (5) climate change; (6) changes in biogeochemical cycles; (7) land-use changes; and (8) biodiversity changes, in addition to some categories identified from the data, such as (9) positive changes and (10) other changes (Figure 3). Each student response was classified into different categories and the percentages of the categories were calculated, taking into account the number of students (128). 


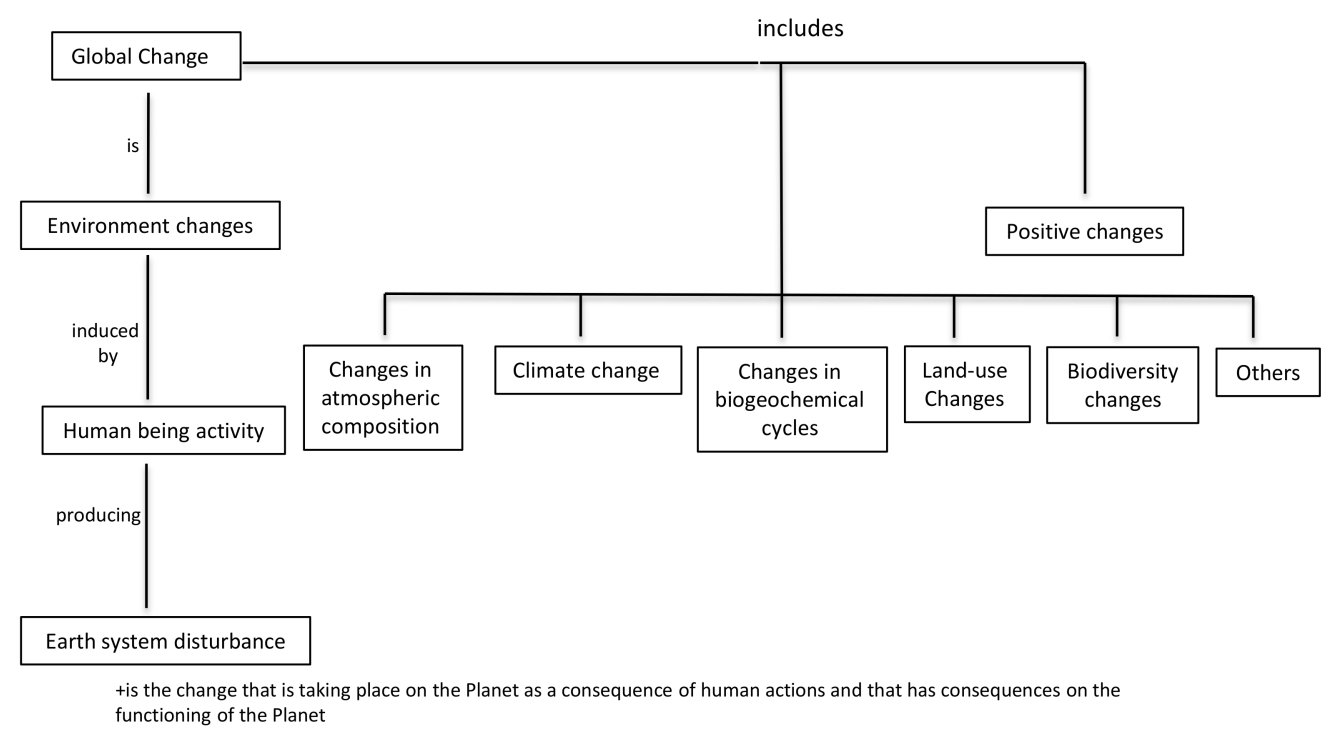

Figure 3. Scheme used to determine categories in the question: What is global change and what consequences does it have? Source: adapted from Duarte et al. [10].

In the second question, ideas concerning the activities that contribute to the GC were classified into categories and items, where the categories were inferred from the data, and finally quantified taking into account the number of students (128). According to the students' answers, the categories established based on the responses to this question involved: (1) plastic use; (2) paper use; (3) car use; (4) non-renewable energies; (5) gas production; (6) water waste; (7) throw-away items; (8) meat consumption; (9) failure to recycle; (10) forest burning; (11) natural-resource exploitation; (12) textile use; and (13) deforestation.

In order to explore student engagement, after finishing the game, the students answered one open-ended question regarding their general opinion of its value. This question was deliberately open-ended to encourage the students to reflect on both what was learned and the learning process itself. The answers from the students regarding the quality of their learning experience allowed for the determination of the indicators of engagement [11,78]. This survey asked:

Q3. What was your experience of playing the A Planet Near the Abyss game?

Initially, students' comments on the game played for both learning and entertainment were used to explore the students' learning experiences. For this analysis, we used core words related to learning (e.g., "educational", "insightful" and "informative") and entertainment (e.g., "fun", "enjoyable").

To assess the strength of the student engagement, we used the dimensions of engagement framework, based on Lorenzoni et al. [37], for climate change. In our case, we related these dimensions to GC. The players' feedback that indicated their reaction to or feeling towards the game, was categorized as "cognitive involvement", "emotional involvement" or "behavioural involvement", which were taken to reflect engagement, as suggested by Lorenzoni et al. [37]. Based on these authors, we defined these categories as:

- Cognitive involvement: what people know or think about GC, and how much mental effort they are willing to expend to understand it.

- Emotional involvement: what and how strongly people feel about GC.

- Behavioural involvement: what and how much people do to address GC.

Finally, the game performance was established against the framework of engagement regarding climate-change-related issues through serious gaming [59]. The framework encompasses 15 main attributes that would make the most impact on user engagement at the cognitive, emotional, and behavioural levels. The results of the students' learning experience were compared with these attributes, establishing the engagement value of the game. 


\section{Results}

\subsection{Validation Phase}

The answers of the questionnaires filled out by the future secondary teachers (Figure 4) were analysed in a quantitative manner and some statistical parameters (mean and variance) were calculated. Figure 4 shows that the future teachers encountered difficulties in understanding the instructions and had to return to them or ask for help while playing. Despite this, they claimed that playing the game was easy. In general, the gameplay was evaluated positively. These evaluators agreed that the number of players, the type of game, the duration of the game, and its purpose were adequate, while the dynamics of the game were assessed as inappropriate due to the disagreement of the participants over some of the rules. The majority considered the game entertaining and valued the contents of the game very positively. According to these future teachers, the game develops key competencies, as well as skills related to environmental issues. The overall assessment mean of the game was six and the majority of the future teachers declared that maybe they would use this resource.

After analysing the results of the questionnaires and taking into account the opinions of the evaluators and their proposals, we made certain changes in the game to improve the instructions and its dynamics.

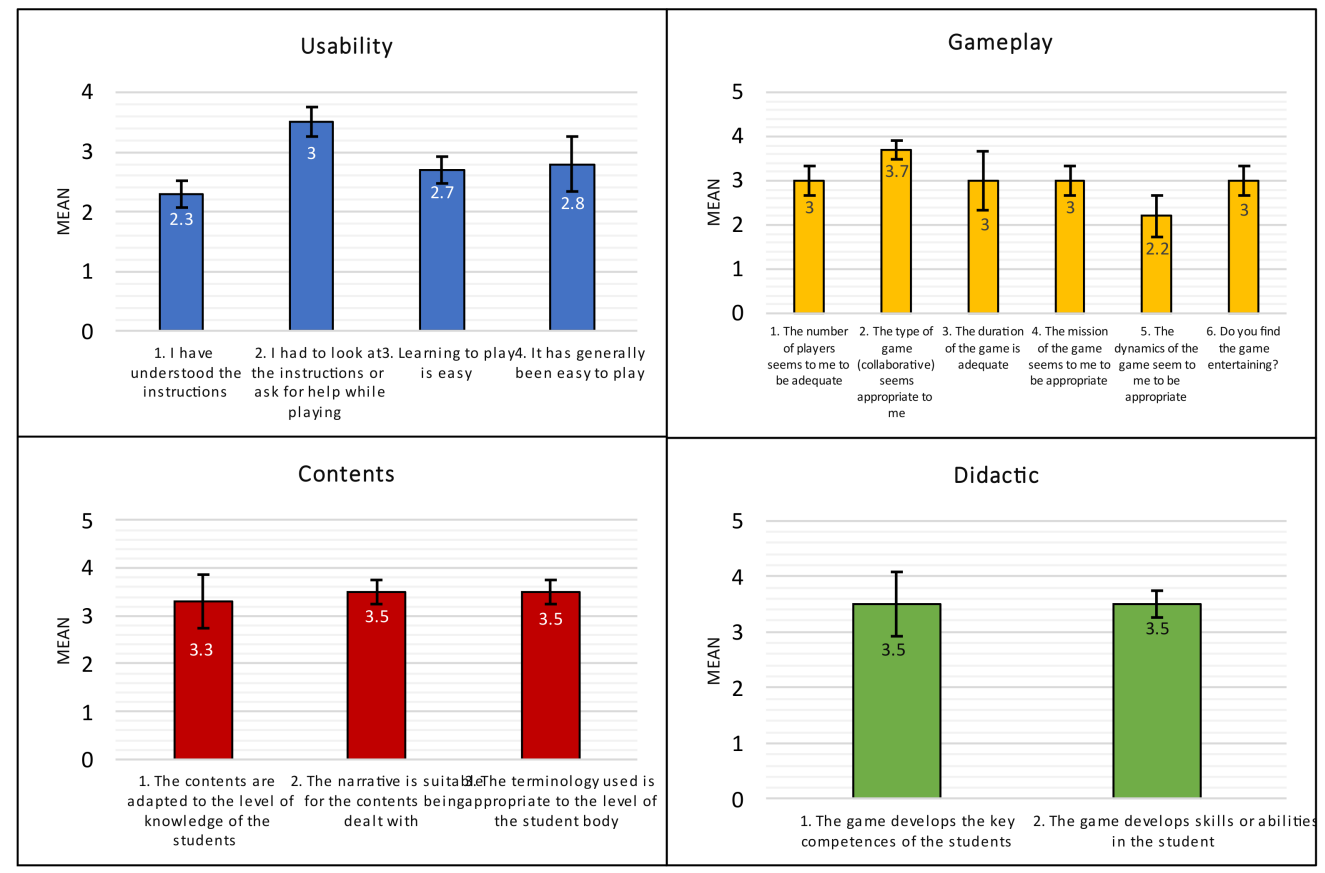

Figure 4. Evaluation of usability and communicative and educational elements of the game (adapted from Ouariachi et al. [75]).

\subsection{Users' Learning Performance}

Figure 5 lists the categories and their frequencies used in the analysis in the question, Q1: "What is GC and what consequences does it have?". In the pre-test, most students $(50 \%)$ considered causes of GC to be induced by humans through pollution, the destruction of the ozone layer, and the greenhouse effect, leading to global warming. In this sense, the answers obtained expressed that GC is the transformation the planet is undergoing due to the actions of human beings. Its consequences are the destruction of the ozone layer, temperature changes, the greenhouse effect, and the melting of the poles (Participant 66). 


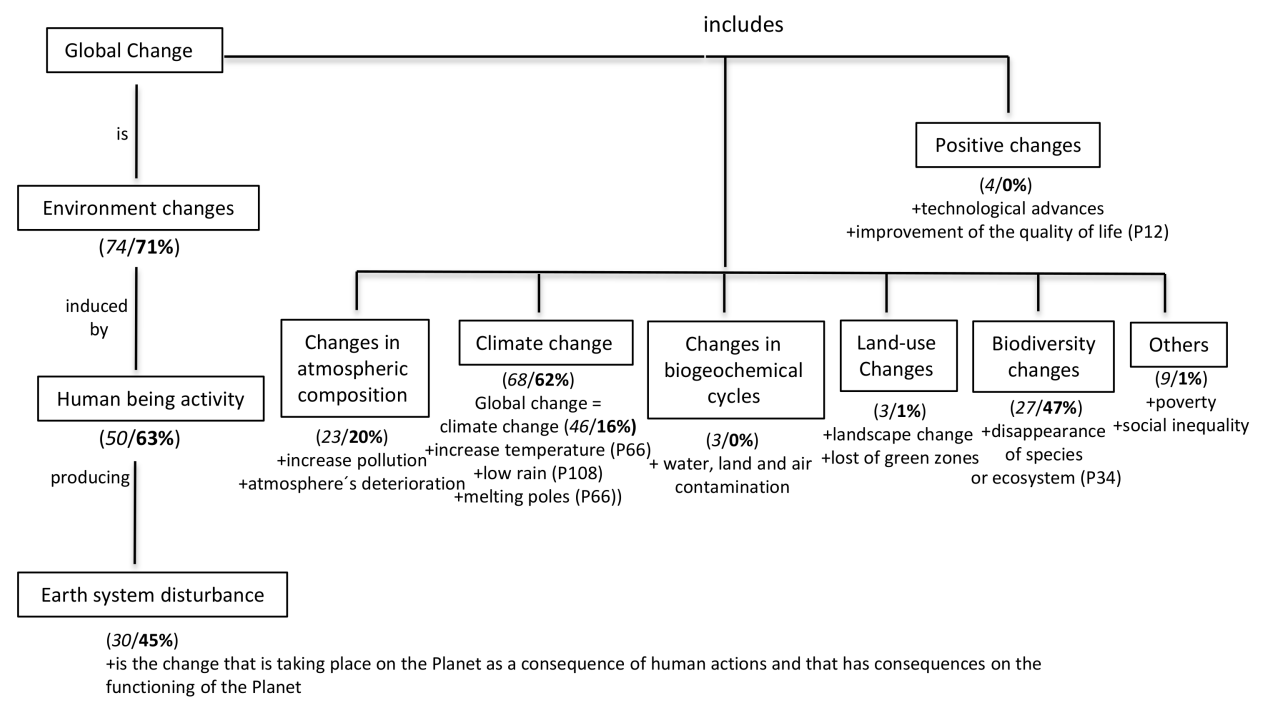

Figure 5. Scheme used to determine categories in the question: What is global change and what consequences does it have? Examples are marked by a "+" and they are related to the participant number (P). The category frequencies in pre-test (in italics) and post-test (in bold), are respectively shown in terms of percentage. Source: adapted from Duarte et al. [10].

Many students (46\%) confused GC with climate change or were only able to establish a relationship with this factor. Mostly, the consequences they named were the thawing of the poles and the increase in Earth's temperature. Examples of these answers indicated that GC is the process by which weather changes abruptly, for example, when in the winter season we might find very high temperatures. The consequences are usually droughts, insufficient rain or excess rain, tidal waves, and floods (Participant 108).

A few students (4\%) confused GC with globalization and/or described it as a change that has negative and positive consequences, such as technological advances. In this way, some students thought that GC encompasses all those changes that occur on the planet due to human intervention. As far as the consequences are concerned, students were able to draw both positive and negative conclusions. Negative: deterioration of the land and the atmosphere or positive: improvement of quality of life (Participant 12).

After playing, some participants (16\%) still defined GC as climate change and did not relate it to the other factors. However, there was an increase in student users of the game $(63 \%)$ who added human activity to their definition, recognizing that it is an environmental change related to the loss of biodiversity and/or the destruction of ecosystems (47\%). Some students responded that GC is the actions that human beings perform, and which affect the entire world. They thought that these included consequences such as the disappearance of some species or ecosystems (Participant 34).

The students who did not know how to define GC or who defined it as something positive before using the game, afterwards gained a clear idea that the consequences of this change are negative. Changes in biogeochemical cycles and land use were practically ignored by the students, while they cited changes in atmospheric composition and climate change with a similar frequency in the pre and post-test phases.

Table 1 shows the frequencies of the categories and items determined from the answers to the question, Q2: "Do you think that something you do affects GC? If yes, indicate what." Some students appeared to find it difficult to recognize that their daily activities could affect GC while others instead described actions in favour of the environment such as recycling or saving water. In the pre-test, some students (54\%) recognized that they used the car when they could use public transportation or other means that do not pollute and/or they did not recycle (32\%). After playing the game, students recognized that some of their daily activities increased GC, mainly the use of a car $(68 \%)$, or failure to recycle $(42 \%)$; however, they cited the use of non-renewable energy and the use of plastics 
with similar a frequency in the pre-test and post-test. Only the water waste category decreased significantly after the game. To a lesser extent, a few students mentioned other potentially harmful personal actions, such as meat consumption or textile use and cited general problems such as burning forests.

Table 1. Frequencies of the categories or items determined in the question: Do you think that something you do has to do with Global Change? If yes, indicate what".

\begin{tabular}{lcc}
\hline \multicolumn{1}{c}{ Category/Items } & Pre-Test (\%) & Post-Test (\%) \\
\hline Plastic use & 17 & 15 \\
Paper use & 4 & 1 \\
Car use & 54 & 68 \\
Non-renewable energies use & 24 & 21 \\
Gas production & 14 & 14 \\
Waste water & 21 & 11 \\
Throw away waste & 17 & 11 \\
Consumption of meat & 1 & 2 \\
Do not recycle & 32 & 42 \\
Forest burning & 0 & 1 \\
Natural resource use & 5 & 4 \\
Textile use & 1 & 2 \\
Deforestation & 2 & 0 \\
\hline
\end{tabular}

\subsection{User Experience of Playing and Engagement}

The participants' responses indicated that the majority of the student users of the game considered, A Planet Near the Abyss, both educational and entertaining. In fact, the feedback of $95 \%$ of the students revealed engagement in learning and $68 \%$ thought that the game was entertaining. The students commented that they learned very important things about the Earth and became aware of the danger that our actions have for our planet through the game in a fun and interesting way (Participant 10).

In their responses, many students (55\%) used educational as well as entertaining core words (fun, entertaining, dynamic, educative, didactic, educational). The students acknowledged that the game is quite good, being both educational and entertaining, so that they were playing and learning at the same time (Participant 90).

The results in this research indicate that a majority of the students (66\%) felt that their thinking was stimulated during playing the game. Student responses suggest that through this game, the students were engaged cognitively with game-based learning. The participants recognized that the game helped them to understand the importance of protecting the ecosystems of our planet to save species. They also commented that the game is very ingenious and original, and full of meaning and information (Participant 67).

Emotional responses were detected in $34 \%$ of the students using the game, indicating that a significant percentage of the students were emotionally engaged. The students indicated that the game raised awareness of damaged ecosystems because the affected board cards show how damage makes the world ugly and that it opened their eyes to the seriousness of the issue (Participant 100).

A few students (24\%) showed behavioural engagement. They recognized that the need for collaboration between all players in order to save the planet in the game, represents a parallel to reality since that is what we are trying to achieve in our real world (Participant 34).

\section{Discussion}

The research findings were further assessed against a framework of climate change engagement through serious games [59], relating the students' answers to established attributes proven to prompt deep engagement (Figure 6).

In the first instance, our game poses achievable challenges. The challenges presented to players in our game, as well as the behavioural change promoted in the messages, are 
within reach of the players, as proposed by Waddington and Fennewald [69]. The results after the game was finished indicated that the players performed well during the game and that they felt good after resolving difficult tasks, thereby attaining the goal of the game. Therefore, the game is challenging. They commented that the game foments deep learning about GC. In fact, after playing, most students added human activity to their definition of GC. They recognized that it is an environmental change and that it began partly as a consequence of the loss of biodiversity and/or the destruction of ecosystems.

In terms of behaviour, our game encourages behaviour-specific changes that are possible and easy to undertake in the real world. The players remarked that collaboration, of the type this game inculcates, is a critical issue for mitigating GC. In this sense, studies have also shown that one of the greatest barriers to pro-environmental behaviour is a sense that individual efforts are insufficient to combat environmental crises such as climate change [79]. Consequently, some social movements are maturing, for example, the FridaysForFuture movement (FFF), where efforts are focused on promoting social change by going beyond the individual toward a collective agency [80], which is in accordance with this game's objective of cooperation.

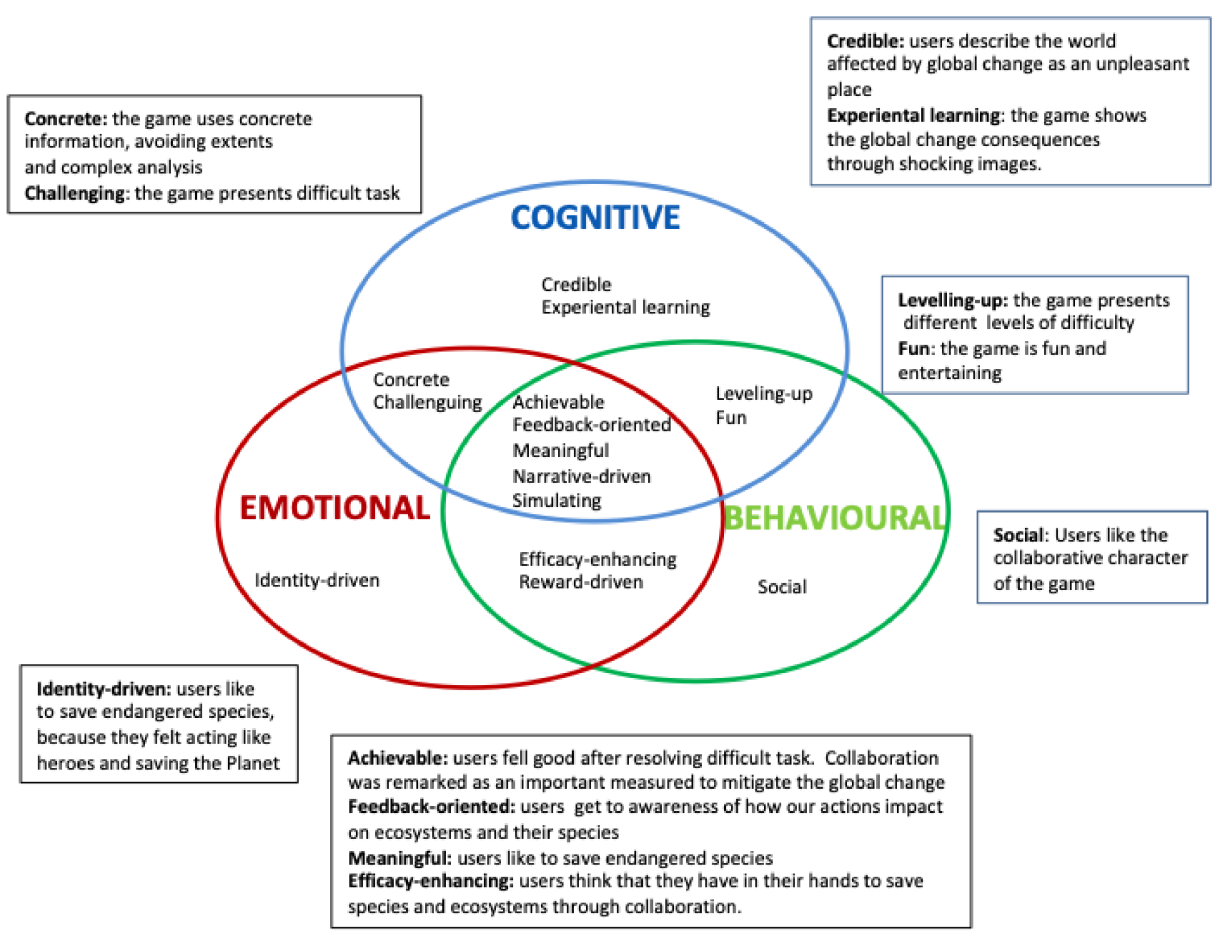

Figure 6. Students' experiences playing the game, A Planet Near the Abyss, mapped against a framework of climate change engagement through serious games. Source: adapted from Ouariachi et al. [59].

Moreover, after playing, our students expressed greater awareness about the environmental crisis; indicated also by an increase of awareness about the daily activities that they recognized as contributing to GC. Hence, their feelings of personal responsibility for the environment increased after playing, implying potential future pro-environmental behaviours. This result is consistent with those reported, for example, by Schroth et al. [81] which showed that through game, users increase their local responsibility for climate change issues.

The problem of GC can frequently leave people feeling powerless. The answers from the student users indicated that after playing they felt that we all have a certain power to save species and ecosystems through collaboration. Therefore, the game proved to be efficacy enhancing and promoted a feeling of empowerment. 
People may often regard GC as an invisible problem, so to experience the problem is the best way to address it. The game presented here is based on experiential learning, since the narrative-driven aspect and design of the game show GC consequences through shocking images of different ecosystems which players must save before those habitats disappear.

Our game includes concrete and credible challenges, which are connected to the real life of students. Users remarked that the images show how the world could be after GC. They described this world as an unpleasant place, showing emotional pathways triggered by the game, therefore, according to the students, the game presents trustworthy information. In addition, the $A$ Planet Near the Abyss game has a levelling-up quality by presenting different levels of difficulty (low, intermediate and advanced).

The consequences of decisions and actions taken in the game simulate the feedback that players receive and replicate in real life, and this feedback should be positive and encouraging [59]. Thus, the game's challenges are feedback oriented. The students enjoyed resolving the game challenges and they recognized that the game helped raise their awareness of how the actions of individuals can have an impact on ecosystems and their species.

Educational games, to be effective, should involve some degree of entertainment and fun [82]. Many students in our research showed in their answers that our educational game was fun and entertaining.

The images and the messages in games can provoke fear and concern, and these feelings need to be counterbalanced with hopeful feelings. Therefore, games can provoke meaningful emotions about GC. Moreover, games should appeal to players' identities-not only to the people they are right now, but also to the people they would like to become [71]. In this sense, many students stated that they enjoyed saving the endangered species, because they felt as though they were acting like heroes and saving the planet. Thus, our game can trigger emotional responses in its players.

The social element is present in our game in its cooperative character. Many students enjoyed the cooperative nature of the game instead of competitive strategies. In this sense, feeling the recognition of and gaining a sense of belonging to a group, could be facilitated by the cooperative character of the game, allowing for the development of intrinsic motivations [42].

The attributes present in our game, such as its being achievable, feedback oriented, meaningful, and narrative driven can be seen as valuable for increasing the potential to engage participants at the cognitive, emotional, and behavioural levels simultaneously (Figure 6), in agreement with Ouariachi et al. [59]. Moreover, these authors have indicated that the more attributes are involved in the design of a game, the stronger physical and mental connections it builds with participants, and the greater the potential will be to influence human behaviour.

\section{Conclusions}

Users' learning outcomes demonstrated that our game improved the understanding of the consequence of human activity, such as biodiversity loss and ecosystem destruction. In addition, the findings indicate that playing can promote a sense of personal responsibility for the environment. In this sense, the students in their responses indicated a pronounced increase in this feeling of responsibility, particularly in relation to car use and recycling, indicating potential pro-environmental behaviour.

Players developed strong emotional, cognitive, and behavioural engagement. The game prompted emotional engagement, where a balance between positive and negative sentiments promoted a feeling of empowerment. The cognitive engagement that was generated sharpened the students' awareness of human activity as a major driver of GC. Behavioural engagement was also fomented, since cooperation, one characteristic of the board game, was recognized as key to mitigate GC, leading to a behavioural change in the participants. 
Our game presents numerous attributes related to the engagement framework proposed by Ouariachi et al. [59]. These attributes are achievable, concrete, credible, challenging, fun, meaningful, social, efficacy enhancing, narrative-driven, feedback oriented, and identity-driven, offering experiential learning in a levelling-up context. These attributes are related to developing engagement at the cognitive, emotional, and behavioural levels. Therefore, the proposed game has a strong potential to influence human behaviour. Thus, our results reaffirm the value of games for educators.

Regarding the limitations of this work, we recognize that it is a small-scale study conducted over a short period. Therefore, a long-term experiment would be helpful to compile follow-up data needed to assess the impact of behavioural shifts over time [11]. More time to play in combination with greater exposure to the board-game context could also have multiplied the learning impact [22], given primarily that a key goal of our game is to promote the understanding of a complex phenomenon comprising GC causes, impacts, and possible actions. Another limitation involves the low frequency of the answers of the students regarding "water waste", "meat consumption" and "textile use" and some GC components (e.g., biogeochemical cycles changes and land use changes). This low incidence rate could be related to the small number of challenges related to these issues within the game, constituting a weakness in its design.

Author Contributions: Conceptualization, M.V.-V., D.G.-R., B.P.-F. and A.F.-O.; Data curation, M.V.-V. and D.G.-R.; Formal analysis, M.V.-V., D.G.-R. and A.F.-O.; Methodology, M.V.-V. and A.F.-O.; Resources, M.V.-V. and A.F.-O.; Supervision, M.V.-V. and A.F.-O.; Visualization, M.V.-V. and A.F.-O.; Writing-original draft, M.V.-V., D.G.-R., B.P.-F. and A.F.-O.; Writing-review \& editing, M.V.-V. and A.F.-O. Project administration, M.V.-V. and A.F.-O. Funding acquisition, M.V.-V. and A.F.-O. All authors have read and agreed to the published version of the manuscript.

Funding: This research was funded by University of Granada, grant numbers PPJI2018-06, PID 18-363 and PBID-19-67, and Junta de Andalucía (Spain), research group HUM-613.

Institutional Review Board Statement: The study was conducted according to the guidelines of the Declaration of Helsinki.

Informed Consent Statement: Informed consent was obtained from all subjects involved in the study.

Data Availability Statement: The data presented in this study are available on request from the corresponding author. The data are not publicly available due to privacy.

Conflicts of Interest: The authors declare no conflict of interest.

\section{References}

1. Oliver, M.C.; Adkins, M.J. “Hot-headed" students? Scientific literacy, perceptions and awareness of climate change in 15-year olds across 54 countries. Energy Res. Soc. Sci 2020, 70, 101641. [CrossRef]

2. Jaén, M.; Barbudo, P. Evolución de las percepciones medioambientales de los alumnos de educación secundaria en un curso académico. REurEDC 2010, 7, 247-259. [CrossRef]

3. Hines, J.M.; Hungerford, H.R.; Tomera, A.N. Analysis and Synthesis of Research on Responsible Environmental Responsible Behavior: A Meta-Analysis. J. Environ. Educ. 1986, 18, 1-8. [CrossRef]

4. Bamberg, S. Changing environmentally harmful behaviors: A stage model of self-regulated behavioral change. J. Environ. Psychol. 2013, 34, 151-159. [CrossRef]

5. Hunecke, M.; Blöbaum, A.; Matthies, E.; Höger, R. Responsibility and environment: Ecological norm orientation and external factors in the domain of travel mode choice behavior. Environ Behav. 2001, 33, 830-852. [CrossRef]

6. Cottrell, S.P.; Meisel, C. Predictors of personal responsibility to protect the marine environment among scuba divers. In Proceedings of the Northeastern Recreation Research Symposium, New York, USA, 6-8 April 2003; pp. $252-261$.

7. Falkenberg, T.; Babiuk, G. The status of education for sustainability in initial teacher education programmes: A Canadian case study. Int. J. Sustain. High. Educ. 2014, 15, 418-430. [CrossRef]

8. Sureda-Negre, J.; Oliver-Trobat, M.; Catalan-Fernández, A.; Comas-Forgas, R. Environmental education for sustainability in the curriculum of primary teacher training in Spain. Int. Res. Geogr. Environ. Educ. 2014, 23, 281-293. [CrossRef]

9. Cook, R.; Cutting, R.; Summers, D. If Sustainability Needs New Values, Whose Values? Initial Teacher Training and the Transition to sustainability. In Sustainability Education: Perspectives and Practice across Higher Education; Jones, P., Selby, D., Sterling, S., Eds.; Earthscan: New York, NY, USA, 2010; pp. 313-327. 
10. Duarte, C.M.; Abanades, J.C.; Agustí, S.; Alonso, S.; Benito, G.; Ciscar, J.C.; Valladares, C.F. Cambio Global. Impacto de la Actividad Humana Sobre El Sistema Tierra; Consejo Superior de Investigaciones Científicas (CSIC): Madrid, Spain, 2006.

11. Fernández-Galeote, D.; Rajanen, M.; Rajanen, D.; Legaki, N.Z.; Langley, D.J.; Hamari, J. Gamification for climate change engagement: Review of corpus and future agenda. Environ. Res. Lett. 2021, 16, 063004. [CrossRef]

12. Bakhuys-Roozeboom, M.; Visschedijk, G.; Oprins, E. The effectiveness of three serious games measuring generic learning features. Br. J. Educ. Technol. 2015, 48, 83-100. [CrossRef]

13. Di Bitonto, P.; Roselli, T.; Rossano, V.; Frezza, E.; Piccinno, E. An educational game to learn type 1 diabetes management. In Proceedings of the 18th International Conference on Distributed Multimedia Systems, Miami, FL, USA, 9-11 August 2012; pp. 139-143.

14. Shaffer, D.W. How Computer Games Help Children Learn; Palgrave Macmillan: New York, NY, USA, 2006.

15. Gee, J.P. What video games have to teach us about learning and literacy. Comput. Entert. 2003, 1, 20. [CrossRef]

16. Stokes, L.C.; Selin, N.E. The Mercury Game: Evaluating a Negotiation Simulation that Teaches Students About Science-Policy Interactions. J. Environ. Stud. Sci. 2014, 6, 597-605. [CrossRef]

17. Harker-Schuch, I.E.; Mills, F.P.; Lade, S.J.; Colvin, R.M. $\mathrm{CO}_{2}$ peration-Structuring a 3D interactive digital game to improve climate literacy in the 12-13-year-old age group. Comput. Educ. 2020, 144, 103705. [CrossRef]

18. Girard, C.; Ecalle, J.; Magnan, A. Serious games as new educational tools: How effective are they? A meta-analysis of recent studies. J. Comput. Assist. Learn. 2013, 29, 207-219. [CrossRef]

19. Bellotti, F.; Kapralos, B.; Lee, K.; Moreno-Ger, P.; Berta, R. Assessment in and of serious games: An overview. Adv. Hum. Comput. Interac 2013, 2013, 136864. [CrossRef]

20. Gatti, L.; Ulrich, M.; Seele, P. Education for sustainable development through business simulation games: An exploratory study of sustainability gamification and its effects on students' learning outcomes. J. Clean. Prod. 2019, 207, 667-678. [CrossRef]

21. Plass, J.; Homer, B.; Kinzer, C. Foundations of game-based learning. Educ. Psychol. 2015, 50, 258-283. [CrossRef]

22. Wouters, P.; van Nimwegen, C.; van Oostendorp, H.; van der Spek, E.D. A metaanalysis of the cognitive and motivational effects of serious games. J. Educ. Psychol. 2013, 105, 249-265. [CrossRef]

23. Young, M.; Slota, S.; Cutter, A.; Jalette, G.; Mullin, G.; Lai, B.; Simeoni, Z.; Tran, M.; Yukhymenko, M. Our princess is in another castle: A review of trends in serious gaming for education. Rev. Educ. Res. 2012, 82, 61-89. [CrossRef]

24. Fabricatore, C.; Lopez, X. Sustainability learning through gaming: An exploratory study. Electron. J. E-Learn. $2012,10,209$.

25. Nurmi, J.; Knittle, K.; Ginchev, T.; Khattak, F.; Helf, C.; Zwickl, P.; Castellano-Tejedor, C.; Lusilla-Palacios, P.; Costa-Requena, J.; Ravaja, N.; et al. Engaging Users in the Behavior Change Process with Digitalized Motivational Interviewing and Gamification: Development and Feasibility Testing of the Precious. JMIR Mhealth Uhealth 2020, 8, e12884. [CrossRef]

26. Lizzio, A.; Wilson, K. Feedback on assessment: Students "perceptions of quality and effectiveness". Assess. Eval. High. Educ. 2008, 33, 263-275. [CrossRef]

27. Trigueros, R.; Aguilar-Parra, J.M.; Lopez-Liria, R.; Cangas, A.J.; González, J.J.; Álvarez, J.F. The Role of Perception of Support in the Classroom on the Students' Motivation and Emotions: The Impact on Metacognition Strategies and Academic Performance in Math and English Classes. Front. Psychol. 2019, 10, 2794. [CrossRef] [PubMed]

28. Cooper, S.; Treuille, A.; Barbero, J.; Leaver-Fay, A.; Tuite, K.; Khatib, F.; Snyder, A.; Beenen, M.; Salesin, D.; Baker, D.; et al. The challenge of designing scientific discovery games. In Proceedings of the Fifth International Conference on the Foundations of Digital Games, Monterey, CA, USA, 19-21 June 2010; pp. 40-47.

29. Csikszentmihalyi, M. Flow: The Psychology of Optimal Experience; Harper Row: New York, NY, USA, 1991.

30. Brown, E.; Cairns, P. A Grounded Investigation of Game Immersion. In Proceedings of the Conference on Human Factors in Computing Systems of Vienna, Vienna, Austria, 24-29 April 2004; pp. 1297-1300.

31. Yee, N. Motivations for Play in Online Games. Cyberpsychol. Behav. 2006, 9, 772-775. [CrossRef] [PubMed]

32. Jimerson, S.R.; Campos, E.; Greif, J.L. Toward an understanding of definitions and measures of school engagement and related terms. Calif. School Psychol. 2003, 8, 7-27. [CrossRef]

33. Lan, X.; Ponitz, C.C.; Miller, K.F.; Li, S.; Cortina, K.; Perry, M.; Fang, G. Keeping their attention: Classroom practices associated with behavioral engagement in first grade mathematics classes in China and the United States. Early Child Res. Q 2009, 24, 198-211. [CrossRef]

34. Skinner, E.A.; Belmont, M.J. Motivation in the classroom: Reciprocal effect of teacher behavior and student engagement across the school year. J. Educ. Psychol. 1993, 85, 571-581. [CrossRef]

35. Newmann, F.M. Student Engagement and Achievement in American Secondary Schools; Teachers College Press: New York, NY, USA, 1992.

36. Connell, J.P.; Wellborn, J.G. Competence, autonomy, and relatedness: A motivational analysis of self-system processes. In The Minnesota Symposia on Child Psychology; Gunnar, M.R., Sroufe, L.A., Eds.; Lawrence Erlbaum Associates Inc.: Hillsdale, NJ, USA, 1991; Volume 23, pp. 43-77.

37. Lorenzoni, I.; Nicholson-Cole, S.; Whitmarsh, L. Barriers Perceived to Engaging with Climate Change among the UK Public and Their Policy Implications. Glob. Environ. Chang. 2007, 17, 445-459. [CrossRef] 
38. Mattheiss, M.D.; Kickmeier-Rust, C.M.; Steiner, D.A. Motivation in game-based learning: It's more than 'flow'. In Lernen im Digitalen Zeitalter, Proceedings of the Workshop-Band Dokumentation der Pre-Conference zur DeLFI2009_Die 7. E-Learning Fachtagung Informatik der Gesellschaft für Informatik e.V., Berlin, Germany, 14-17 September 2009; Schwill, A., Apostolopoulos, N., Eds.; Logos Verlag: Berlin, Germany, 2009; pp. 77-84.

39. Shu, L. Student Engagement in Game-Based Learning: A Literature Review. Master's Thesis, The University of Texas at Austin, Austin, TX, USA, 2018; p. 53.

40. Buckley, P.; Doyle, E. Gamification and student motivation. Interact. Learn. Environ. 2016, 24, 1162-1175. [CrossRef]

41. Fischer, C.; Malycha, C.; Schafmann, E. The Influence of Intrinsic Motivation and Synergistic Extrinsic Motivators on Creativity and Innovation. Front. Psychol. 2019, 10, 137. [CrossRef]

42. Mahmud, S.N.D.; Husnin, H.; Tuan Soh, T.M. Teaching Presence in Online Gamified Education for Sustainability Learning. Sustainability 2020, 12, 3801. [CrossRef]

43. Broer, J.; Breiter, A. Potentials of Gamification in Learning Management Systems: A Qualitative Evaluation. In Design for Teaching and Learning in a Networked World; Conole, G., Klobučar, T., Rensing, C., Konert, J., Lavoué, E., Eds.; EC-TEL, Lecture Notes in Computer Science; Springer: Cham, Germany, 2015; Volume 9307, pp. 389-394. [CrossRef]

44. Ekici, M. A systematic review of the use of gamification in flipped learning. Educ. Inf. Technol. 2021, 6, 3327-3346. [CrossRef]

45. Kan, B.; Tan, S. Interactive Games: Intrinsic and Extrinsic Motivation, Achievement, and Satisfaction. J. Manag. Strategy 2014, 5, 110-116.

46. Tsai, J.C.; Liu, S.Y.; Chang, C.Y.; Chen, S.Y. Using a Board Game to Teach about Sustainable Development. Sustainability 2021, 13, 4942. [CrossRef]

47. Tsai, J.C.; Cheng, P.H.; Liu, S.Y.; Chang, C.Y. Using board games to teach socioscientific issues on biological conservation andeconomic development in Taiwan. J. Balt. Sci. Educ. 2019, 18, 634-645. [CrossRef]

48. Flood, S.; Cradock-Henry, N.A.; Blackett, P.; Edwards, P. Adaptive and interactive climate futures: Systematic review of 'serious games' for engagement and decision-making. Environ. Res. Lett. 2018, 13, 063005. [CrossRef]

49. Rajanen, D.; Rajanen, M. Climate change gamification: A literature review. In Proceedings of the GamiFIN 2019 Conference, Levi, Finland, 8-10 April 2019; pp. 253-264. Available online: http://ceur-ws.org/Vol-2359/paper22.pdf (accessed on 26 October 2021).

50. Powell, K.C.; Kalina, C. Cognitive and social constructivism: Developing tools for an effective classroom. Education 2009, 130, 241-250.

51. Monroe, M.C.; Plate, R.R.; Oxarart, A.; Bowers, A.; Chaves, W.A. Identifying effective climate change education strategies: A systematic review of the research. Environ. Educ. Res. 2017, 25, 791-812. [CrossRef]

52. Eisenack, K. A climate change board game for interdisciplinary communication and education. Simul. Gaming 2013, 44, 328-348. [CrossRef]

53. Cheng, P.H.; Tsai, J.C.; Chen, S.Y.; Chang, C.Y. Learning transfer to daily habit: The design and effectiveness of water resources board Game. J. Environ. Educ. Res. 2020, 16, 1-36.

54. Cheng, P.H.; Yeh, T.K.; Tsai, J.C.; Lin, C.R.; Chang, C.Y. Development of an Issue-Situation-Based Board Game: A Systemic Learning Environment for Water Resource Adaptation Education. Sustainability 2019, 11, 1341. [CrossRef]

55. Ozge-Arslan, H.; Moseley, C.; Cigdemoglu, C. Taking attention on environmental issues by an attractive educational game: Enviropoly. Procedia Soc. Behav. Sci. 2011, 28, 801-806. [CrossRef]

56. Martin, G.; Felten, B.; Duru, M. Forage rummy: A game to support the participatory design of adapted livestock systems. Environ. Model. Softw. 2011, 26, 1442-1453. [CrossRef]

57. Jiménez-Aleixandre, M.P.; Gallástegui-Otero, J.R. 'Let's Save Energy!': Incorporating an environmental education dimension in the teaching of energy. Environ. Educ. Res. 2006, 1, 75-83. [CrossRef]

58. Ouariachi, T.; Chin-Yen, L.; Elving, W. Gamification Approaches for Education and Engagement on Pro-Environmental Behaviors: Searching for Best Practices. Sustainability 2020, 12, 4565. [CrossRef]

59. Ouariachi, T.; Olvera-Lobo, M.D.; Gutiérrez-Pérez, J.; Maibach, E. A framework for climate change engagement through video games. Environ. Educ. Res. 2018, 25, 701-716. [CrossRef]

60. Pérez-Fernández, B. Un planeta en el abismo: Propuesta para la educación científica en bachillerato a través de un juego de mesa sobre el cambio global. Official University Master's Degree in Compulsory Secondary Education and Baccalaureate Teaching Staff, Professional Training and Language Teaching. University of Granada, 2019, p.59. Available online https://digibug.ugr.es/handle/10481/53824 (acceded on 23 October 2021).

61. Chappin, E.J.; Bijvoet, X.; Oei, A. Teaching sustainability to a broad audience through an entertainment game-The effect of catan: Oil springs. J. Clean. Prod. 2017, 156, 556-568. [CrossRef]

62. Rumore, D.; Schenk, T.; Susskind, L. Role-play simulations for climate change adaptation education and engagement. Nat. Clim. Change 2016, 6, 745-750. [CrossRef]

63. Onencan, A.M.; Enserink, B.; Van de Walle, B. Sustainability indicators: Monitoring cross-county water cooperation in the Nzoia river basin, Kenya. Sustainability 2019, 11, 560. [CrossRef]

64. Dieleman, H.; Huisingh, D. Games by which to learn and teach about sustainable development: Exploring the relevance of games and experiential learning for sustainability. J. Clean. Prod. 2006, 14, 837-847. [CrossRef] 
65. Hamari, J.; Shernoff, D.J.; Rowe, E.; Coller, B.; Asbell-Clarke, J.; Edwards, T. Challenging games help students learn: An empirical study on engagement, flow and immersion in game-based learning. Comput. Human Behav. 2016, 54, 170-179. [CrossRef]

66. Squire, K. Video games in education. Int. J. Intell. Games Simul. 2003, 2, 49-62.

67. Salen, K.; Zimmerman, E. Rules of Play: Game Design Fundamentals; The MIT Press: Cambridge, MA, USA, 2004.

68. Pérez-Fernández, B.; Vázquez-Vílchez, M.; Fernández-Oliveras, A. A Proposal for Global-Change Education based on an educational board game: A Planet on the Abyss, ERPA International Congresses on Education 2019 (ERPA 2019). SHS Web Conf. 2019, 66, 01029.

69. Waddington, D.I.; Fennewald, T. Grim FATE: Learning about systems thinking in an in-depth climate change simulation. Simul. Gaming 2018, 49, 168-194. [CrossRef]

70. Morris, B.J.; Croker, S.; Zimmerman, C.; Gill, D.; Romig, C. Gaming Science: The “Gamification” of Scientific Thinking. Front. Psychol. 2013, 4, 607. [CrossRef]

71. Heath, C.; Heath, D. Switch: How to Change Things When Change Is Hard; Random House Busines, Broadway Books: New York, NY, USA, 2010.

72. Brooke, J. SUS: A quick and dirty usability scale. In Usability Evaluation in Industry; Jordan, P.W., Thomas, B., Weerdmeester, B.A., McClelland, I.L., Eds.; Taylor and Francis: London, UK, 1996; pp. 189-194.

73. Nemoto, T.; Beglar, D. Likert-scale questionnaires. In Proceedings of the JALT 2013 Conference Proceedings, Tokio, Japan, 12-15 November 2013; Nemoto, T., Beglar, D., Eds.; Japan Association for Language Teaching: Tokio, Japan, 2013; pp. 1-8.

74. Wolfe, E.W.; Smith, E.V., Jr. Instrument development tools and activities for measure validation using Rasch models: Part I-Instrument development tools. J. Appl. Meas. 2007, 8, 97-123.

75. Ouariachi, T.; Olvera-Lobo, M.D.; Gutiérrez-Pérez, J. Evaluación de juegos online para la enseñanza y aprendizaje del cambio climático. Enseñanza De Las Cienc. 2017, 35, 193-214. [CrossRef]

76. Braun, V.; Clarke, V. Using thematic analysis in psychology. Qual. Res. Psycho. 2006, 3, 77-101. [CrossRef]

77. Schreier, M. Qualitative Content Analysis in Practice; SAGE, EEUU: Los Angeles, CA, USA, 2012.

78. Emblen-Perry, K. Enhancing student engagement in business sustainability through games. Int. J. Sustain. High. Educ. 2018, 19, 858-876. [CrossRef]

79. Axon, S. "Keeping the ball rolling": Addressing the enablers of, and the barriers to, sustainable lifestyles. J. Environ. Psychol. 2017, 52, 11-25. [CrossRef]

80. Francesconi, D.; Symeonidis, V.; Agostini, E. FridaysForFuture as an Enactive Network: Collective Agency for the Transition Towards Sustainable Development. Front. Educ. 2021, 6, 636067. [CrossRef]

81. Schroth, O.; Angel, J.; Sheppard, S.; Dulic, A. Visual climate change communication: From iconography to locally framed 3D visualization. Environ. Commun. 2014, 8, 413-432. [CrossRef]

82. Yamada, F.M.; Ribeiro, T.; Pirani Ghilardi-Lopes, N. Assessment of the prototype of an educational game on climate change and its effects on marine and coastal ecosystems. Rev. Bras. Inform. Educ. 2019, 27, 1-31. [CrossRef] 